\title{
STUDY OF CONSTRUCTIVE PROVISION OF THE CAPSULE FORMATION PROCESS OF THE «OIL AND FAT RAW MATERIALS - IONOTROPIC SHELL-MAKER» SYSTEM
}

\author{
Olga Neklesa \\ Department of technology of bread, confectionery, pasta and food concentrates \\ Kharkiv State University of Food Technology and Trade \\ 333 Klochkivska str., Kharkiv, Ukraine, 61051 \\ olgapyvovarova52@ukr.net \\ Yvgennia Yarantseva \\ Department of Food Technology \\ Kharkiv State University of Food Technology and Trade \\ 333 Klochkivska str., Kharkiv, Ukraine, 61051 \\ Korotayeva1990@gmail.com \\ Yevgen Pyvovarov \\ Department of Food Technology \\ Kharkiv State University of Food Technology and Trade \\ 333 Klochkivska str., Kharkiv, Ukraine, 61051 \\ pcub@ukr.net \\ Olga Grinchenko \\ Department of Food Technology \\ Kharkiv State University of Food Technology and Trade \\ 333 Klochkivska str., Kharkiv, Ukraine, 6105I \\ grinoly@gmail.com
}

Abstract

The effectiveness of fundamental and applied research is realized in the field of technological and hardware solutions, it allows creating a new generation of food products whose quality indicators go beyond those typical of the traditional assortment. This to a certain extent applies to the fat and oil industry.

An important scientific and at the same time practical result is the proposal to consider the encapsulation process not only from the technological point of view. This requires a scientific approach both in the choice of the components of the food system, and in the realization of their properties under the prevailing conditions. From a practical point of view, this determines the given technical and constructive solutions

To date, there is no theory and practice of extrusion of two fluids through the "air" technological medium, one of which is flowable oil content, and the other is a solution of the ionotropic polysaccharide. There are no scientific and technical principles for the formation of the physical form of the capsule, as well as industrial devices for their production. Food technologies with the use of fat-and-oil raw materials encapsulated are not revealed, and information on the effect of a new food form of fat-and-oil raw materials on the formation of product quality indicators in the technological flow and during storage is not generalized.

To obtain a controlled technological process for the production of fat-and-oil encapsulated raw material, it is important to provide laminar flow of ionotropic shell-maker and fat-and-oil raw materials along the product line of the encapsulation device. This is possible under the condition of special constructive maintenance of the process of capsule formation of the "fat-and-oil raw materials - ionotropic shell-maker" system. This served as the basis for determining the physical parameters of the formation of a thermostable capsule. It is proved that the formation of a final capsule with internal contents of fat-and-oil raw material is possible under the condition of an individual design of an extrusion head and a capsulation device that ensure the circumferential rotation of the capsule in the laminar flow of the receiving medium. This allows to form capsules with given organoleptic, commodity, technological properties and the like.

Keywords: capsule formation process, sodium alginate, calcium alginate, extrusion head, device for encapsulation. 


\section{Introduction}

The strategic measures of food safety formulated in Ukraine, the growth in the volume of food production and the improvement of the structure of nutrition can't fully resist the vectors of the influence of the world economy on the trends in the development of food markets [1]. This is prompted by the pronounced dependence of Ukraine on the import of a huge number of food products and related products for the creation of food systems. This applies, in particular, to products with pronounced functional and technological properties, which is manufactured with the use of structure-forming agent, foaming agents, emulsifiers, etc. [2]. The use of such food systems allows to quickly enter the Ukrainian market of products in the presence of technologies of modern methods of food production. But this leads to absolute dependence in the food sphere and, as a result, the need for forced "copying" of technologies that are built on such principles.

In our opinion, the only opportunity to resist the importation of food systems and technologies in the Ukrainian market is the development of new technologies with high added technological value. Such technologies, as shown by marketing research, include technology of encapsulation of food products and systems in edible shells based on polysaccharides that can be called as encapsulation of fat-and-oil raw materials [3].

Capsule formation is inherently a transition of homogeneous or microheterogeneous polymer systems with a freely dispersed gel-free state of the gel, a non-flowing two-component system. This system is formed by molecular dispersion of a low molecular weight liquid in a polymer, between which chains there are transverse bonds. The driving forces of such processes are the presence of physical, chemical or simultaneously present physical and chemical potentials and energy interactions.

Common to the known processes of capsule formation of hydrophobic substances is the use of film-forming materials (shell-maker). The basis of this process is the conclusion of substances in the shell that performs the function of disconnecting the components from each other and isolating them from the external environment. This is achieved by phase liquid-liquid separation, polymer crosslinking, polycondensation and polymerization at the interface. The consequence of these processes is the formation of capsules, which are two-phase systems and consist of a shell, preferably solid or gel-like, and internal contents that can be in any aggregate state. But the distinguishing feature of all methods of encapsulation is the thermodynamic incompatibility of the internal environment and the shell-maker, which are traditionally represented by the unipolar non-mixed liquids.

Encapsulation of multi-polar liquids in food technology is a complex technological process. As a rule, this process is reduced to extrusion of a compound mixture with hydrophilic properties ("water") to a hydrophobic medium ("fat and oil raw materials"). In this case, "hot water" is understood as a hot solution of thermotropic gelling agent, which after dosing enters a cooled hydrophobic by the properties phase, where there is an unauthorized formation of the structure with the appearance of the "oil (internal component) - water (gelling agent) - oil (forming medium)" technological system. But because of the difficulties in ensuring the stability of the process of capsule formation, this method leads to a complication of the technological process. This facilitates the extraction of substances into the forming medium with the adjustment of its properties, which results in an increase in the relationship of "water" to the forming medium - "oil" with a disruption in the stability of the process. This necessitates the utilization of the used oil or its purification, the washing of the product made from the oil, significantly limits the spectrum of substances that can be encapsulated, requires strict control of temperature conditions, increases the cost of the final products. An additional restriction on the use of this method is the requirements for "oil" (internal contents): it must consist of triacylglycerides and do not contain fat-soluble surfactants, which include phospholipids of fats and oils.

The first developed and thoroughly studied encapsulation technologies were methods based on the use of gelatin as a film-forming material. It, upon cooling, forms gels with the binding of a considerable amount of moisture and is capable of forming a hard shell of the shell on the surface of the capsules. [4] Providing a limited wetting of the capsule material (fat-and-oil raw material) of the film-forming materials (gelatin solution) during the encapsulation, droplets are formed. As a result of the action of the surface forces, the capsules acquire a spherical shape, the surface of which is enveloped by the shellformed material, which is incompatible with the contents of the capsule. [5] From the physical and chem- 
ical point of view, it is the limited ability to mix reactants that ensures the formation of a clear interface that prevents the spreading of the film-forming material over the surface of the droplets [6].

In the literature [7] it is indicated that the formation of gelatin capsule shells in practice is most often carried out by cooling them in solutions of nonpolar substances (oil). The purpose of this is dissolution prevention of the capsule shell. The mechanism of phase transformations of the gelatin solution consists in changing the conformation of the polymer macromolecules upon cooling and forming a spatial grid of the gel, which is stabilized by hydrogen bonds, hydrophobic and other intermolecular forces. Due to the transition of the system from the liquid to the solid-state, a gel-like capsule shell forms and a spherical shape is fixed.

Unfortunately, the spectrum of substances that can be encapsulated in gelatinous membranes is limited by their polarity, and the capsules themselves have a high lability to the effect of temperature-they are not thermostable, which is due to the gelatin's property of passing into the solution.

The majority of encapsulation technologies are based on the implementation of the principle of thermodynamic incompatibility of components of shell-maker and encapsulant. To encapsulate hydrophobic substances, including fat-and-oil raw materials, use polar solutions of polymers capable under certain conditions to controlled film formation, that is, the formation of the capsule shell. The indicated principle is the basis for the implementation of encapsulation processes and is based on surface phenomena occurring at the interface between phases of non-mixed liquids [8].

When using ionotropic poly-saccharides, for example, sodium alginate (AlgNa) as a reference, there is a need to co-axially extrude, according to the pipe-in-tube principle, a solution of the shell-maker (outer tube) and the hydrophobic substance (inner tube) into the forming medium through air in the state of the formed quasi-stable capsules. Upon entering the receiving environment, chemical potentials are realized and the capsule acquires a commodity state in texture.

The scientific and technical prerequisite for the realization of the direction of encapsulation of food products is the systematic research of the authors [9-11], thanks to which scientific bases of encapsulation based on aqueous solutions have been created. There are no system studies with the purpose of scientific justification of the technology of encapsulation of fat-and-oil raw materials and products with their use.

In connection with the foregoing, the scientific substantiation and development of the principles of constructive provision of the process of capsule formation of the "fat-and-oil raw materials ionotropic shell-maker" system as an obligatory condition for providing a controlled technological process with obtaining products of specified quality is relevant.

\section{Materials and Methods}

In the framework of the study of the structural support of the capsule formation process of the "oil and fat raw materials - ionotropic shell-makers" system, as a subject of research, a device with two-tube extrusion heads is chosen according to the "pipe-in-pipe" principle (Fig. 1, a). Also, the subject of research is encapsulated food products with internal contents of fat-and-oil raw materials.

The photographic image of the investigated samples is shown in Fig. 1, $\boldsymbol{b}$.

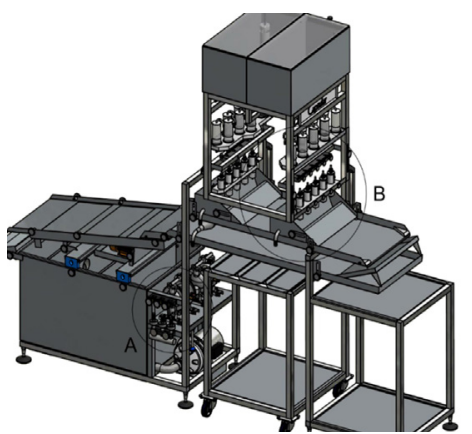

$a$

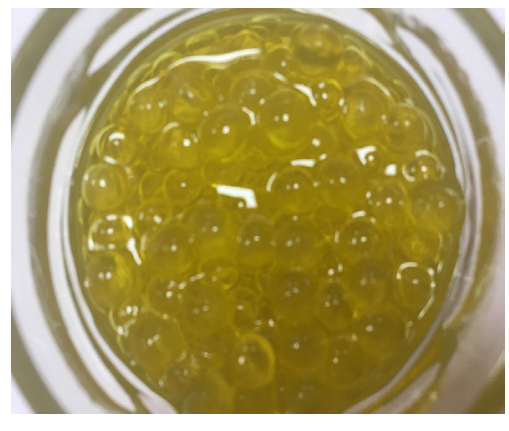

$b$

Fig. 1. Photographic image of research objects: $a$-industrial two-tube device for encapsulation of food lipids, $b$ - investigated encapsulated food lipids 


\section{Results}

Development and implementation of the principles of encapsulation of fat-and-oil raw materials coincides with the world trends in the development of the food industry. According to these trends, the improvement in the structure of nutrition, along with other factors, is determined by the technological stability of oils, fats in time and extended shelf life due to ensuring their intactness with the external environment.

From the practical point of view, the preparation of encapsulated food lipids is achieved by simultaneous coaxial vertical extrusion according to the pipe-in-pipe principle, where an aqueous solution of AlgNa is fed through an outer tube, and oil, fats or mixtures, lipid-based extracts are fed along the outer tube. A method for the capsule formation of hydrophobic substances is developed and the technical solutions for obtaining capsules with internal hydrophobic contents is patented [12, 13].

To ensure a stable process of obtaining encapsulated food lipids, it is important to organize laminar flow of shell-maker and lipids through the product line of the extruder head. Also, it is necessary to ensure the physical formation of quasi-stable capsules during its detachment from the head with a uniform and symmetric distribution of lipid content relative to the center of the capsule by a distribution of lipid content and shell-maker. Ensuring the formation of a physically correct shape and uniform distribution of shell-maker on the surface of the encapsulant is a complex technological and constructive task because of the different density $\left(\rho, \mathrm{kg} / \mathrm{m}^{3}\right)$ of shell-maker and internal contents. This is the reason for the appearance of defects quasi-stable droplet capsules, which are manifested in the case of the lower bridging of the shell-maker with simultaneous loss of thickness in the upper and lateral parts of it. The appearance of physical disproportion of the capsule leads to a complication of the technological process: a decrease in the quality of the finished product.

Elimination of the revealed physical disproportions during the formation of the droplet capsule is achieved by using a specially designed head with a controlled movable inner tube of the product pipeline. This allows to monitor and adjust the thickness of the horizontal walls of the capsule.

According to the technical plan, the dose-drop is formed in the air, and then a dose-drop is formed through the air and is supplied to the forming medium, in which the capsule formation process is completed. The cross-section of the extrusion head of the device for providing a dose-droplet formation is shown in Fig. 2.

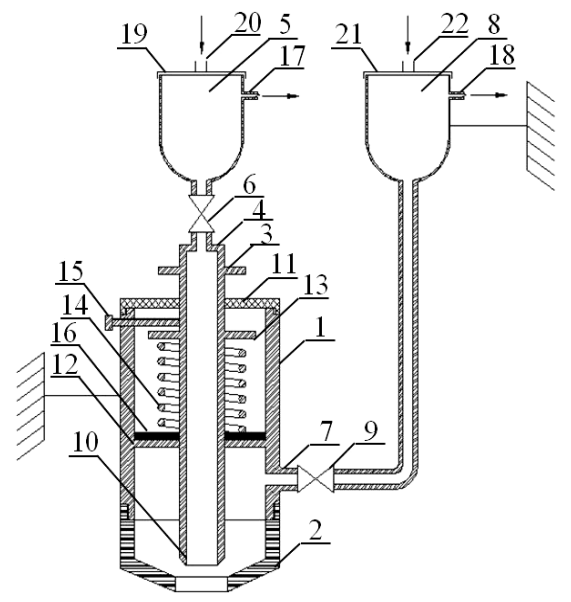

Fig. 2. Cross-section of an extrusion head for encapsulation of food lipids by the "pipe in pipe" principle

In this case, the flow of two liquids proceeds in a continuous flow that obeys the Bernoulli equation for the continuity of jet flow [14].

It has been established that, with justified parameters, the leakage of both liquids and the homogeneity at the outlet 3 and the nozzle will be constant values. This makes it possible to calculate the conditions for a monodisperse controlled rupture of liquids by jet extrusion to droplets with 
constant dimensional characteristics and the phase relationship within the process flow of capsule formation and one batch.

The analysis of Fig. 2 allows to evaluate the principles of action that are placed in the design of the extrusion head for encapsulation and the possibility of regulating the physical symmetry of the shell-maker and the encapsulant. By lowering or lifting the nozzles, the thickness of the horizontal shell parts is quasi-stable capsules. In the lower part of the head there is a confuser 2 with an outlet 3 , and the confuser 2 is removable from the lower part of the body 1 . The inner content feed pipe 4, which is connected on its one side to the body 1 and, on the other, to an intermediate unsealed seal a container for internal contents 5, with which the internal contents enter the inner content feed pipe 4 . The supply branch of the shell-maker 7 is connected to an intermediate unsealed container for shell-maker 8 . The supply of the shell-maker 7 contains a flow control valve of the obturator. The orifice 10 is located coaxially with the outlet 3 and is mounted above it, with the possibility of adjusting the distance between the orifice 10 and the outlet 3 . This design solution is a feature of the extrusion head and comes out of the physical laws, density ( $\rho$ ) of the encapsulant and gellant, which results in the formation of a "one-sided" capsule, it is possible to compensate by the position of the orifice 10 to the outlet 3 . Also, the orifice 10 is installed with the possibility of removing the contents of the inner content feed pipe 4 . In the upper part of the body 1 is a detachable cover 11. In the cavity of the body 1 above the branch of the supply of shell-maker 7 are located: the first lower stop 12, adjacent to the inner surface of the body 1, the second upper stop 13, which adjoins to the outer surface of the supply port of the inner contents 4 and a spring 14 which is clad on the inner content feed pipe 4 and is located between the first lower 12 and the second upper stop 13. The fixing means 15 of the inner content supply pipe 4 in the body 1 is made in the form of a locking screw located in the upper part of the body 1 . The gasket is 16 , which the spring 14 presses against the first lower stop 12. At the top of the intermediate unsealed container for internal contents 5 a lateral branch 17 is located, and a lateral branch 18 is located in the upper parts of the intermediate depressurized container for shell-maker 8. Also, the container for internal contents 5 also contains a cover 19 with the pipe 20 and depressurized orifice for internal contents 5 contains a cover 21 to the nozzle 22. Inlet nozzle 4 comprises internal contents lateral projection 23.

The design and the hydraulic circuit for feeding the extruder head provide spontaneous controlled monodisperse dissolution of liquids in the form of a sphere. The capsules pass through the air into the receiving formation medium of the $\mathrm{Ca}^{2+}$ solution.

\section{Conclusions}

Today, the direction of encapsulation of various raw materials is very relevant in the food and pharmaceutical industry, as evidenced by the numerous scientific studies in the world on this issue. The use of ionotropic polysaccharides allows essentially new properties to be provided to hydrophobic food systems. They provide the production of traditional oils, fats, mixtures in a dosage form and in an independent edible pack. This allows to ensure the perception of lipid raw materials as a product with fundamentally new properties that can change the structure of many technological processes. The method for obtaining seamless capsules with internal contents of fat-and-oil raw materials is substantiated, which made it possible to determine the physical parameters of the formation of a thermostable capsule. It is established that the formation of a final capsule with internal contents of fat-and-oil raw material is possible under the condition of individual structural support of the operation of the extrusion head and the device for encapsulation, the design of which ensures the rotation of the capsule around its axis. This allows to obtain a stable controlled technological process. It has been established that circumcision of the capsule rotation in the laminar flow of the receiving medium allows the formation of capsules with prescribed organoleptic, commodity, technological properties and the like.

Provision of technological and physicochemical stability of fat-and-oil raw materials will meet the growing demand for food products with their use. The new consumer form of a seamless capsule will allow developing both a fundamentally new assortment of culinary products and new technological principles for obtaining food products. The relevance of such research is increasing in connection with the possibility of using new data in the theory and practice of special types of 
nutrition by the controlled release of the inner contents of capsules in the zones of the gastrointestinal tract, as well as in adjacent branches of activity related to human health - medicine, pharmacy, microbiology and other.

Design solutions for devices for encapsulation are developed, carried out experimental development is the basis for developing a technological scheme and justifying the parameters of the technological flow of production of fat-and-oil encapsulated products and, accordingly, adaptation of the new technology in real industrial conditions.

\section{References}

[1] Dauncey, M. J. (2015). Nutrition, Genes, and Neuroscience. Diet and Exercise in Cognitive Function and Neurological Diseases. John Wiley \& Sons, Inc., 1-13. doi: 10.1002/9781118840634.ch1

[2] Fakharian, M.-H., Tamimi, N., Abbaspour, H., Mohammadi Nafchi, A., Karim, A. A. (2015). Effects of $\kappa$-carrageenan on rheological properties of dually modified sago starch: Towards finding gelatin alternative for hard capsules. Carbohydrate Polymers, 132, 156-163. doi: 10.1016/j.carbpol.2015.06.033

[3] Allen, T. M. (2004). Drug Delivery Systems: Entering the Mainstream. Science, 303 (5665), 1818-1822. doi:10.1126/science.1095833

[4] Nikitiuk, V. G., Shemet, N. A. (1999). Istoriia, preimushchestva i sovremennaia klassifikatsiia zhelatinovyh kapsul. Provizor, 2, 32-34.

[5] Pyvovarov, P. P., Hrynchenko, O. O., Pyvovarov, Ye. P., Nahornyi, O. Yu. (25.06.2011). Method for obtaining gelatinous capsules containing fat phase and aqueous one. Patent of Ukraine No. 94959 C2, MPK A23P1/04, A61K9/48. Appl. No. a200901885. Filed 03.03.2009. Bull. No. 12. Available at: http://uapatents.com/4-94959-sposib-oderzhannya-zhelatinovikh-kapsul-z-vmistom-zhirovo-i-vodno-fazi.html

[6] Salazar-Lopez, E. I., Jimenez, M., Salazar, R., Azuara, E. (2015). Incorporation of Microcapsules in Pineapple Intercellular Tissue Using Osmotic Dehydration and Microencapsulation Method. Food and Bioprocess Technology, 8 (8), 1699-1706. doi: 10.1007/s11947-015-1534-8

[7] Peake, N. J., Pavlov, A. M., D’Souza, A., Pingguan-Murphy, B., Sukhorukov, G. B., Hobbs, A. J., Chowdhury, T. T. (2015). Controlled Release of C-Type Natriuretic Peptide by Microencapsulation Dampens Proinflammatory Effects Induced by IL-1 $\beta$ in Cartilage Explants. Biomacromolecules, 16 (2), 524-531. doi: $10.1021 / \mathrm{bm} 501575 \mathrm{w}$

[8] Korotaeva, E. A. (2014). Vliianie komponentnogo sostava na svoistva dvuhsloinoi priiomnoi sredy v tehnologii koaksial'noi vertikal'noi ekstruzii. Kharchova nauka i tekhnolohiia, 2 (27), 45-48.

[9] Plotnikova, R. V. (2011). Rozrobka tekhnolohichnoho protsesu vyrobnytstva napivfabrykativ dlia desertnoi produktsii. Kharchova nauka i tekhnolohiia, 2 (15), 77-82.

[10] Nahornyi, O. Yu. (2014). Theoretical properties of kapsulevvanikh of model systems on basis of NaKMC. Bulletin of the National Technical University «Kharkiv Polytechnic Institute». Series: New solutions in modern technologies, 7 (1051), 92-97.

[11] Grinchenko, N. G., Plotnikova, R. V. (2014). Issledovanie sorbtsionnoi sposobnosti al'ginata natriia s tsel'iu regulirovaniia sostava solevoi sistemy moloka obezzhirennogo. Scientific Letters of Academic Society of Michal Baludansky, 2 (5), 32-35.

[12] Pyvovarov, P. P., Neklesa, O. P., Nagornyi, A. Iu. (2017, June 22). Encapsulating head and device for producing capsules. Patent No. WO 2017105378 A1, MPK A23P (2006.01) A61J 3/07 (2006.01). Appl. No. PCT/UA2016/000146. Filed 2016, December 15. Available at: http://www.google.com/patents/ WO2017105378A1?cl=en\&hl=ru

[13] Neklesa, O. P., Korotaeva, E. A., Pyvovarov, P. P. (10.06.2015). Sposib oderzhannia kapsul z vnutrishnim umistom na osnovi zhyriv ta otrymana na yoho osnovi kapsula. Patent of Ukraine No. 108807, MPK A 23 P 1/00. Appl. No. a 2014 00713. Filed 25.01.2014. Bull. No. 11. Available at: http://uapatents. com/10-108807-sposib-oderzhannya-kapsul-z-vnutrishnim-umistom-na-osnovi-zhiriv-ta-otrimana-na-jjogo-osnovi-kapsula.html

[14] Potapov, V., Neklesa, O., Pyvovarov, P. (2017). Analysis of kinetics pattern in the formation and separation of a drop of fluid in the form of a capsule. Eastern-European Journal of Enterprise Technologies, 2 (10 (86)), 32-40. doi: 10.15587/1729-4061.2017.98537 